\title{
Homicide in southern India-A five-year retrospective study
}

\author{
Sachidananda Mohanty ${ }^{1^{*}}$, Sujan Kumar Mohanty ${ }^{2}$, Kiran Kumar Patnaik ${ }^{1}$ \\ ${ }^{1}$ Department of Forensic Medicine and Toxicology, M.K.C.G. Medical College, Berhampur, India; \\ *Corresponding Author: sachimohanty@rediffmail.com \\ ${ }^{2}$ Department of Forensic Medicine, Minakhi Medical College, Kanchipuram, India
}

Received 31 December 2012; revised 7 February 2013; accepted 25 February 2013

Copyright (C) 2013 Sachidananda Mohanty et al. This is an open access article distributed under the Creative Commons Attribution License, which permits unrestricted use, distribution, and reproduction in any medium, provided the original work is properly cited.

\begin{abstract}
Homicide has become a common practice reflecting anger in southern India. The purpose of this study was to identify the potential risk factors and susceptible victims. This retrospective study analyses the data of $\mathbf{5 9 0}$ cases. Our study revealed that the victims were mostly males of 21 - 30 years, married (63.56\%), illiterates ( $44.07 \%)$, low socioeconomic status and belong to rural areas. The laborers and farmers were almost equally affected in males and housewives in females. Outdoor incidents were more (61.86\%). Majority of victims were innocent (82.20\%) with no previous history of cognizable offence. Blood alcohol was found positive in $\mathbf{3 0 . 2 3 \%}$ of victims. Sharp cutting weapons were mostly used, with hemorrhage and shock being the most common cause of death. Previous enmity and familial disharmony were the two common causes behind such heinous crime. Most victims had injuries over multiple body parts. Some potential risk factors and their preventive measures pointed at the end.
\end{abstract}

Keywords: Autopsy; Homicide; Familial Disharmony; Victim

\section{INTRODUCTION}

Life and death are the two sides of a coin. When there is birth, death is inevitable. While there is only one way to be born, there are many ways to die [1]. Premature death due to disease process is acceptable but deaths as a result of violent crimes are unacceptable to the society.

Violent crimes like murder, dacoity, kidnapping and riots, abduction are nowadays frequently encountered. Among the violent crimes affecting life, homicide/mur- der is the most heinous crime under law. Homicide (homos: human being, caedere: to kill) literally means to kill a human being. Homicide is defined legally as destruction of human life by the act, agencies, procurement or culpable omission of some other person or persons [1] Such activities instil a sense of insecurity and fear in the community and disturb peace and harmony in the society.

In the present day world violence is clearly recognised as a global public health problem. Violence and injuries account for $9 \%$ of global mortality and $12 \%$ of all disability adjusted life years (DALY) [2]. As per Global Burden of Armed Violence Report, 2011 [3], the average annual global violent death rate between 2004 and 2009 was 79 per million. Globally around 520,000 people die each year as a result of interpersonal violence which equates to 1400 deaths every single day.

Regarding homicide, Indian statistics is no way far behind from the world statistics. Even after 65 years of independence, poverty, illiteracy and unemployment have almost crippled lives mostly at the villages. The stigmatised caste system and religious superstitions still prevail. The innocent people can be easily persuaded by local political leaders and fundamentalists to work for their vested interests. This ultimately leads to hatred and empathy among the people. Due to this prevailing unstable socio-economic, political and religious crisis and increase in corruption, the rate of homicide is increasing day by day in geometrical progression in our country. As per National Crime Record Bureau, violent crimes reported in India were $10.9 \%$ of the total Indian Penal Code crimes. The total number of murders recorded all over India in 2010 is 33,335 and in our state, Odisha it is 1308 which is still increasing every year [4].

In this era of rising trends of organised crimes being executed in a professional manner, we may expect the occurrence of such criminal activities to follow a pecu- 
liar pattern in relation to victims, accused, purpose and execution of the crime. Although quite a good number of authoritative works in relation to homicide have already been done in different parts of India [5-12] and in other countries [13-28], only few works have been done from the victims' perspective in this region. The present study has been taken up with an aim to explore different aspects of crime in relation to victims, all possible epidemiologic profile with specific emphasis on the common methods used and causes behind the crime which might pre-empt to initiate preventive measures.

\section{MATERIALS AND METHODS}

This study was carried out over a period of five years starting from $1^{\text {st }}$ November 2006 to $31^{\text {st }}$ October 2011 in the Department of Forensic Medicine and Toxicology, M.K.C.G. Medical College \& Hospital, Berhampur, India.

Being the referral centre, it receives cadavers from the Berhampur city and outskirt villages in the district of Ganjam and also neighboring districts of southern Odisha comprising a population of 1.9 millions approximately. Out of the 8504 medico legal autopsies conducted during the above mentioned period, a total of 590 established homicidal cases were taken as study material. Cases of unnatural deaths where the cause of death could not be ascertained due to insufficient/improper history, gross decomposition and inadequate findings were excluded from the study.

The history and sociological aspects of deceased were obtained from accompanying persons/relatives and police as per the predesigned proforma. Each homicidal case was examined and evaluated at autopsy, both externally and internally. Emphasis was given on presence of any mechanical injury causing death, signs of struggle or defense wounds. Simultaneously Dead bodychallan, Inquest report, Bed head tickets from hospital (if available) were studied. Qualitative estimation of alcohol was carried out in the departmental laboratory by subjecting vitreous fluid to dichromate test to find out the simultaneous intake of alcohol by the victim in all cases except in those cases where vitreous was decomposed, extensive burns and victims of less than 10 years of age.

In the present study, depending on the prevailing standard, socioeconomic statuses were categorized as low, middle and high depending upon the income per family per year i.e. up to Rs 0.1 million as low, Rs 0.1 to Rs 0.3 million as middle and more than Rs 0.3 million as upper. The educational status has been classified as Illiterate who are not able to read or write, Primary-up to class VII, as higher Secondary (from Class VIII-X) and College and above. The victims belonging to areas under Notified area council and Municipal Corporation were considered as urban group while others reporting from Panchayat areas were considered as rural group. To evaluate seasonal occurrence of crime the year was divided into summer (March to June), rainy (July to September) and winter (October to February), which are more or less the main seasons of India.

\section{Statistical Analysis}

Calculations were done using SPSS software in Microsoft excels. The data collected were analysed by using chi-square test. The $p$-value $(p \leq 0.05)$ was considered as statistically significant.

\section{RESULTS}

Out of 8504 medico legal autopsies, 590 cases (6.94\%) were homicides. Males outnumbered females with a ratio of almost 3:1 $(p>0.05)$. The commonest age group of the victims was 21 to 30 years $(p>0.05)$ (Figure 1). Illiterates (44.07\%) and primary educated ones (25.42\%) belonging to low socioeconomic group (61.69\%) were the vulnerable victims $(p>0.05)$ (Table 1). The laborers and farmers were almost equally affected, $23.73 \%$ and $22.03 \%$ respectively followed by housewives $(14.41 \%)$ $(p<0.0001)$. Mostly married victims $(63.38 \%)$ were the sufferers $(p>0.05)$. Quite clearly there was a predominance of homicide in rural areas $(79.66 \%)(p<0.05)$. In $61.86 \%$ cases the incident took place outside the four walls of house $(p<0.0001)$. Maximum incidents took place in the night $(65.42 \%)(p=0.01)$ and during summer $(41.69 \%)(p=0.70)$ (Table 1). Majority of victims were innocents $(82.20 \%)$ and did not have any history of previous assault $(86.44 \%)$. There was no history of associated cognisable offence in most of the incidents $(89.83 \%)$ although history of direct provocation was present in $20.34 \%$ cases. Victims in $30.23 \%$ of cases were found positive for alcohol $(p=0.003)$. Most of the injuries were found at multiple sites $(61.95 \%)$ followed by injury to head \& neck $(26.55 \%)(p=0.02)$. Majority of the

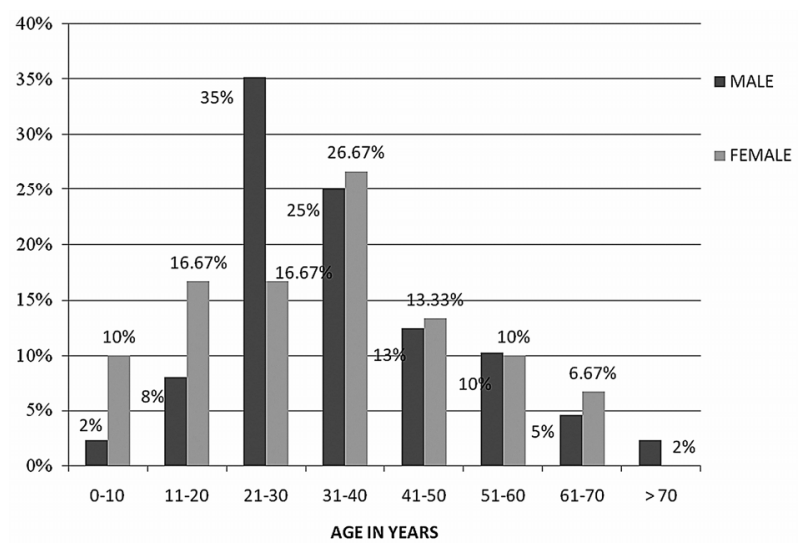

Figure 1. Age \& sex distribution. 
Table 1. Sociological aspects.

\begin{tabular}{|c|c|c|}
\hline \multicolumn{2}{|c|}{ Number of cases } & Percentage $\%$ \\
\hline \multicolumn{3}{|c|}{ Socioeconomic status } \\
\hline Low & 364 & $61.69 \%$ \\
\hline Medium & 150 & $25.42 \%$ \\
\hline High & 46 & $7.80 \%$ \\
\hline Unknown & 30 & $5.08 \%$ \\
\hline Total & 590 & $100 \%$ \\
\hline \multicolumn{3}{|c|}{$\chi^{2}=3.06$, d. f. $=2, p<0.2$} \\
\hline \multicolumn{3}{|l|}{ Education } \\
\hline Illiterate & 260 & $44.07 \%$ \\
\hline Primary & 150 & $25.42 \%$ \\
\hline High School & 100 & $16.95 \%$ \\
\hline College & 50 & $8.47 \%$ \\
\hline Unknown & 30 & $5.08 \%$ \\
\hline Total & 590 & $100 \%$ \\
\hline \multicolumn{3}{|c|}{$\chi^{2}=1.90$, d. f. $=3, p=0.59$} \\
\hline \multicolumn{3}{|l|}{ Marital status } \\
\hline Married & 374 & $63.38 \%$ \\
\hline Unmarried & 180 & $30.51 \%$ \\
\hline Widow & 10 & $1.69 \%$ \\
\hline Divorcee & 06 & $1.02 \%$ \\
\hline Unknown & 20 & $3.39 \%$ \\
\hline Total & 590 & $100 \%$ \\
\hline \multicolumn{3}{|c|}{$\chi^{2}=6.94$, d. f. $=3, p=0.07$} \\
\hline \multicolumn{3}{|l|}{ Area of distribution } \\
\hline Rural & 470 & $79.66 \%$ \\
\hline Urban & 90 & $15.25 \%$ \\
\hline Unknown & 30 & $5.08 \%$ \\
\hline Total & 590 & $100 \%$ \\
\hline \multicolumn{3}{|c|}{$\chi^{2}=4.32$, d. f. $=1, p=0.03$} \\
\hline \multicolumn{3}{|l|}{ Diurnal variation } \\
\hline 6 am - 6pm (day) & 194 & $32.88 \%$ \\
\hline $6 \mathrm{pm}-6$ am (night) & 386 & $65.42 \%$ \\
\hline Unknown & 10 & $1.69 \%$ \\
\hline Total & 590 & $100 \%$ \\
\hline \multicolumn{3}{|c|}{$\chi^{2}=5.68$, d. f. $=1, p=0.01$} \\
\hline \multicolumn{3}{|l|}{ Seasonal variation } \\
\hline Nov-Feb (Winter) & 130 & $22.03 \%$ \\
\hline Mar-Jun (Summer) & 246 & $41.69 \%$ \\
\hline July-Oct (Rainy) & 214 & $36.27 \%$ \\
\hline Total & 590 & $100 \%$ \\
\hline \multicolumn{3}{|c|}{$\chi^{2}=0.70$, d. f. $=2, p=0.70$} \\
\hline
\end{tabular}

cases $(66.95 \%)$ did not show any defence wounds $(p=$ $0.01)$. Sharp cutting weapons $(36.61 \%)$ were most commonly used followed by hard and blunt ones $(24.41 \%)(p$ $=0.004)$ (Table 2). Hemorrhagic shock $(44.07 \%)(p=$ $0.05)$ followed by cranio-cerebral injuries $(34.58 \%)$ were the common causes of death (Figure 2). Previous enmity $(35.59 \%)$ was the most common cause followed by familial disharmony $(18.65 \%)$ and property dispute $(14.23 \%)$ $(p=0.001)$ (Table 3).

\section{DISCUSSION}

More often than not homicide is well planned; hence not usually adequately witnessed. In this context, it becomes difficult to elucidate the truth which mostly relies on linking the act of crime to the criminal, basing on scientific/circumstantial evidences. This creates a challengeable task for the investigating agencies to explore the mystery. As the investigation to a case of homicide will be incomplete without thorough analysis and scientific interpretation of autopsy findings, the responsibility of forensic medicine specialist is of immense importance to recognise the medico legal injuries in their right perspective and help the investigating authorities and the judiciary for their legal conclusions.

Table 2. Weapons used.

\begin{tabular}{ccc}
\hline Weapons Used & No of cases & Percentage \\
\hline Sharp Cutting & 216 & $36.61 \%$ \\
Hard \& Blunt & 144 & $24.41 \%$ \\
Firearm & 86 & $14.58 \%$ \\
Strangulation & 20 & $3.39 \%$ \\
Thermal & 54 & $9.15 \%$ \\
Multiple & 60 & $10.17 \%$ \\
Others & 10 & $1.69 \%$ \\
Total & 590 & $100 \%$ \\
\hline
\end{tabular}

$\chi^{2}=19.01$, d. f. $=6, p=0.004$

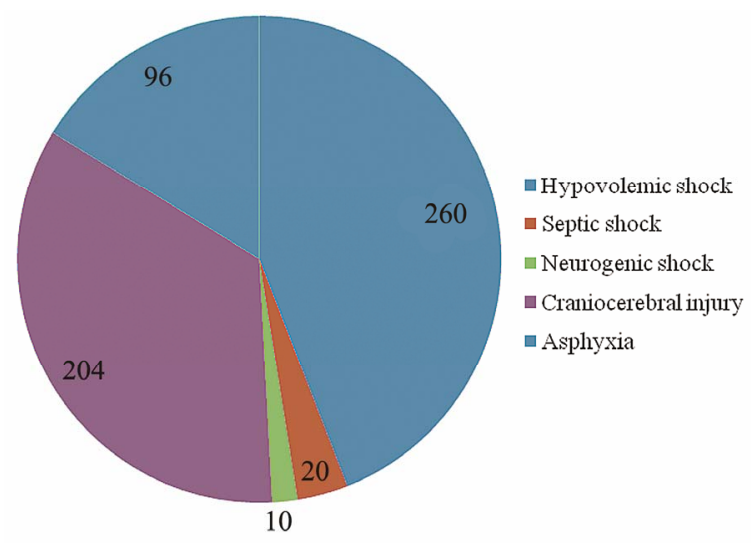

Figure 2. Causes of death. 
Table 3. Causes of homicide.

\begin{tabular}{ccc}
\hline Causes of homicide & Number of cases & Percentage \% \\
\hline Previous Enmity & 210 & $35.59 \%$ \\
Property Dispute & 84 & $14.23 \%$ \\
Familial Disharmony & 110 & $18.65 \%$ \\
Love Affair & 20 & $3.39 \%$ \\
Dowry & 16 & $2.71 \%$ \\
Robbery & 10 & $1.69 \%$ \\
Criminal Rivalry & 04 & $0.68 \%$ \\
Gang War & 06 & $1.02 \%$ \\
Sudden Emotional & 10 & $1.69 \%$ \\
Outburst & 10 & $1.69 \%$ \\
Rape \& Murder & 110 & $18.65 \%$ \\
Unknown & 590 & $100 \%$ \\
Total & & \\
\hline
\end{tabular}

$\chi^{2}=28.88$, d. f. $=10, p=0.001$.

Our study revealed overall percentage of homicide cases to be $6.94 \%$ of all medico legal autopsies, while earlier reports from other parts of India have projected it to be $2.83 \%-4.12 \%$ [15]. Studies conducted elsewhere on this revealed a low percentage of incidences in Nigeria [13], South Carolina, USA [14] where as a high percentage (7.4\%) of homicide was detected in Poland [15]. However a high percentage (21\%) was detected while studying on Turkish population [16]. This increases in the trends of homicide in India over the years could be due to increase in population, industrialisation and urbanization superimposed by poverty and animosity.

Among the sufferers the males outnumbered females with ratio being almost $3: 1$. Highest number of cases reported from 21 - 30 years (30.51\%) followed by 31 40 years $(25.42 \%)$ (Figure 1). Study in the neighbouring countries like Pakistan $[17,18]$ and Malaysia $[19,20]$ revealed almost similar finding whereas study in Sri Lanka [21] detected a male predominance similar to our study. However the common age detected was between 18 - 40 years. A study conducted in South Africa [22] revealed predominance of males (82\%) and the most susceptible age group was $21-40$ years (50\%). Studies conducted in African countries like Nigeria [13] suggested a male predominance with common age of victims being $20-40$ years. Studies in other countries like Turkey [16] revealed that males are usual victims $(83.06 \%)$ and in Poland [15], Ireland [23] also stated a male predominance with common age between 20 - 35 years. Earlier studies in India [6-8] almost revealed similar results as our study with regard to sex and age. Studies at other places of Indian subcontinent [5,9-12] suggested male predominance with percentage varying from $60 \%$ to $80 \%$ and contributes $40 \%$ to $60 \%$ of total number of cases in $21-30$ years age group which corroborates with our finding.

The causes for male predominance may be because of their number, unemployment, jealousy, revenge, lack of patience, intake of alcohol and bad accomplices, etc. The lower incidence in females is mainly attributed to custom, social values and preference of females to stay indoors. The common age of the victims was $21-30$ years. The probable causes in males could be effect of vibrant attitude, non-obedience and the attitude of taking law in hands, where as in females early marriage, dowry, sexual assaults appear to be the common causes of this locality.

In the ongoing study, Hindus were $97.46 \%$ and rest of the religions like Christianity and Muslims account for $2.5 \%$ similar to studies in India $[11,12]$. This may be explained by the fact that the religion of most of the population of this locality is Hinduism.

Our study revealed that the low socioeconomic group of individuals are the major victims $(61.69 \%)$ followed by the medium income group (25.42\%) (Table 1). It may be reasonable to attribute illiteracy, unemployment, high mobility in search of work, despair and frustration in the low socioeconomic group to prompt a criminal behavior.

In our study $44.07 \%$ victims were from illiterate background followed by victims from primary educated group $(25.42 \%)$ (Table 1). This is similar to the finding reported from Berhampur, India [8]. But contrary to our study, the highest percentage of sufferers was detected from literate group at some urban areas of India $[6,10]$. This could be related to poverty, unemployment, large family, prevalence of multicast system of the society and inability to solve the dispute by fruitful peaceful discussions.

We observed that most of the victims were either laborers $(23.73 \%)$ or farmers $(22.03 \%)$ among males and housewives (14.41\%) among females. However a study conducted in Malaysia [20] revealed $71.9 \%$ of the victims were from semiskilled and unskilled workers.

In the present study, $63.38 \%$ victims were married. Similar findings were observed in Malaysia [20] and in India $[8,10]$ (Table 1). A study undertaken in Poland [15] however pointed out that single male and married female were the common sufferers. The attributing cause in our study could be marital disharmony, disbelief and lack of understanding, poverty, early marriage and alcohol to a great extent, as per the interrogation reports.

In our study we have encountered maximum deaths from rural area (79.66\%). Studies on this in Germany [24] and in western India [6] suggested an urban predominance. But studies conducted in the eastern India [12] suggested rural predominance $(69.69 \%)$. The rural predominance could be attributed to poverty, unemployment, illiteracy, lack of entertainment, early marriage and easy 
availability of alcohol, etc.

It was observed that in $61.86 \%$ cases, the act was committed outside the house of the victims. Study conducted on this in Greece [25], and other parts of India $[6,12]$ also found outdoor to be the common place of occurrence similar to our study while studies in Canada [26], USA [27], and Ireland [23] pointed out an indoor occurrence.

We observed that majority of incidents had taken place at night $(65.42 \%)$ very similar to some studies in London [28] and India $[6,7,10]$. But in contrast, studies in Malaysia [19] and Sri Lanka [21] pointed out maximum occurrence during morning and day time respectively. This could be attributed to less risk of identification in the darkness, chance of confrontations during day, abuse of alcohol and other substances at night.

We observed that most cases were reported during summer $(41.69 \%)$ followed by rainy season $(36.27 \%)$. Studies in Pakistan [17], London [28], India [5,10] observed similar incidence in summer. But a study in Poland [15] revealed no such seasonal variation and at Delhi [7] revealed an even distribution in summer and winter. Due to erratic seasonal variation with extended summer season and unpredictability of rainy season affecting this locality, the farmers and agricultural workers and other people related to this field belonging normally to lower strata of society are practically rendered jobless. Poverty, debts and loans may lead to extreme situations resulting homicide.

In our study most victims were innocents $(82.20 \%)$ without having any past history of criminal activities, which led us to an assumption that the weak and innocents are more vulnerable to the crime. Literature perused on this so far does not speak much on these factors, however in this locality causes like alcohol addiction, loss of temper for petty differences and illiteracy appears to be responsible for assaults on innocents.

After evaluation of victims for any associated cognizable offence we found that in almost $90 \%$ of cases there is no history of association of any other cognizable offence. Studies at Nigeria [13] and Alabama, USA [27] stated that mostly robbery was associated with murder. In many instances, these associated cognisable offences led to the crime or vice versa. In our study, robbery, theft and organised crimes are less in comparison to studies in other countries as stated above. The reason for assaults leading to loss of life in this area could be due to illiteracy, disdainful attitude towards legal procedures.

However in $20.34 \%$ of cases there was direct provocation of accused by the victims. In majority of cases $(65.25 \%)$ the provocation could have been misinterpreted because of the insufficient history given by relatives, acquaintances or police. Study in Ireland [23] stated that arguments and quarrel preceded the crime in most of the cases. In India, study at Delhi [7] suggested violent rage or quarrel preceded the act of crime in $29 \%$ of cases and study at Mangalore, India [9] pointed out that in $52.8 \%$ of cases the perpetrator had a pre planned motive. The less provocation may point to the planning beforehand and hatred among the perpetrators. Though less, but arguably cases due to direct provocation can be explained by the lower intelligent quotient of the poor illiterate people, who fall prey to slight provocation starting with a simple quarrel.

In our study, we detected that more than half of the victims $(51.7 \%)$ were addicted to various substances and the most common being alcohol and tobacco. To know the consumption of alcohol prior to the act, qualitative estimation of alcohol in vitreous fluid was done and the result reveals that $30.23 \%$ of victims were found positive for alcohol. Study in Canada [26] pointed out 54\% of victims tested positive for blood alcohol whereas studies at Turkey [16] (7.58\%) suggested very low incidence and other parts of India [8] predicted incidence as high as $40.93 \%$. In our study victims are addicted to tobacco and alcohol due to socio-cultural practices which in turn decreases the threshold of inhibition and potentially provocation the victims to be aggressive and quarrelsome leading to violence.

As regards the sites of injuries are concerned, we found in our study that majority $(61.95 \%)$ of injuries at multiple sites followed by injury to head \& neck (26.55\%). Studies at Pakistan [18] revealed chest to be the commonest site of injury, explained by common use of firearms. Studies from Nigeria [13] and western India [8] pointed out injuries at multiple body sites at par with our study. However studies from other parts of India $[9,11]$ suggested head and neck injuries to be the most common site, which contradicts our view. The reasons for inflicting injuries at multiple sites are firm determination on the part of the perpetrator to be very sure that the victim is dead or will not recover later on. Sometimes extreme hatred may lead to over killing. Other factors like involvement of multiple assailants or just because the victim goes on fighting for a longer duration cannot be ruled out.

We observed that defense wounds were present in $25.42 \%$ of cases. Studies in Germany [24] and Delhi, India [7] observed a low incidence of defense wounds, a very similar result like ours. However, a high rate of defense wound $39.9 \%$ was detected by a study undertaken at Aurangabad, India [10]. The absence of defense wounds in majority of the cases can be attributed to factors like involvement of multiple assailants, assault during sleep or intoxication and unexpected attack.

Our study revealed sharp cutting weapons (36.61\%) followed by hard and blunt weapons $(24.41 \%)$ were most commonly being used (Table 2). Studies conducted at 
different places like in Malaysia [20], Canada [26], Ireland [23] and India [5-7,9] suggested similar findings. But studies conducted in our neighbouring country Pakistan [17,18], Nigeria [13] and Turkey [16] revealed fire arms to be the most commonly used weapon followed by sharp cutting ones. In contrast, some studies from Malaysia [19], and other parts of India [8,10-12] reported dissimilar findings. The increasing use of sharp cutting weapons by the people of this region could well be explained by the fact that these weapons are more dangerous than blunt weapons and are easily available due to agricultural background and at the same time non availability of firearms.

On subsequent evaluation for various causes of death, we noticed that hemorrhagic shock (44.07\%) followed by craniocerebral injuries (34.58\%) were the two most common cause of death (Figure 2) which is in confirmative with the studies undertaken at Nigeria [13] and India $[5,8,9,11]$. The reason for this can be attributed to the type of weapons used, pattern, distribution and severity of injuries and the body parts involved.

We observed in our study that previous enmity $(35.59 \%)$, familial disharmony $(18.65 \%)$ and property dispute $(14.23 \%)$ are the major precipitating factors for homicide (Table 3). Worldwide literature on this showed a varied picture. A study in Germany [24] found that most acts were conducted to conceal crime followed by personal conflicts. Study at Alabama, USA [27] cited robbery was the motive behind the crime while study in Ireland [23] suggested arguments followed by domestic quarrel being the chief cause. Indian scenario on this also varies. Similar to our study, previous enmity was observed at Bengaluru [6] and at Aurangabad [10] whereas study at Ahmedabad [5] reported domestic quarrel (41\%) followed by dispute over money (16\%), Delhi [7] observed violent rage or quarrel and provocation, Surat [8] observed revenge (31.61\%), Mumbai [11] found revenge and property dispute, Berhampur, Odisha [12] opined personal factors $(58.21 \%)$ and revenge are the most common precipitating factors behind the heinous crime. Familial disharmony arises due to lack of mutual understanding among couples, poverty, and sexual deprivation/aberration, fear of infidelity ultimately ending with the violent act.

\section{CONCLUSIONS}

Trends of homicide differ from country to country, region to region and from time to time. The social and cultural values along with demographic variables affect the crime. At the same time illiteracy, poverty and mistrust worsen the scenario.

In our multi-approach study, we observed that the socially active young males and females were mostly the sufferers. The uneducated laborers and farmers of rural population belonging to the lower socioeconomic strata were mostly affected. Most incidents took place outside during night, that too in summer season. Most victims were assaulted by sharp weapons and defense wounds were not present commonly. Previous enmity is the most common cause followed by familial disharmony. Alcohol intoxication significantly adds to the list of causes of rise in homicide.

Up to date knowledge of the prevailing trends of homicide may help the law makers in preventing homicides, though this could be a Himalayan task. But to decrease the rates of homicide substantially, certain fruitful steps can be taken like uplifting the social life of the poor, alleviating illiteracy by rural educational programs, providing better job opportunities, prohibition or restricted sale of alcohol, safe guarding their interests and rights, awareness programmes to eradicate various superstitions, etc. Along with the socioeconomic improvement, the crime investigating agencies including medico legal aspects and judiciary system is to be strengthened so that the laws can be enforced stringently. A wide range of further investigation especially on the effects of surroundings, inherent characteristics and psychiatric illness can be carried out on the victims to point out some more predisposing factors which on use can prevent homicide to a large extent.

Assessing the burden of the issue on the socio-economical, cultural and multidirectional after effects, we feel that continuous research in this field is the need of the hour, to divulge various factors and implement strategies to prevent loss of innocent lives.

\section{ACKNOWLEDGEMENTS}

We are thankful to Dr. Asim Mishra for his help and guidance during the preparation of this manuscript.

\section{REFERENCES}

[1] Adelson, L. (1974) The pathology of homicide. Charles C Thomas, Springfield, 3-4.

[2] Krug, E. (2003) Message of Support: Summary Annual Report 2003. Medical Research Council, South Africa.

[3] Global Burden of Armed Violence Report (2011). http://www.genevadeclaration.org/measurability/global-b uden-of-armed-violence/global-burden-of-armed-violence -2011.html

[4] NCRB Records (2010) http://ncrb.gov.com

[5] Padmaraj, R.Y. and Tandon, R.N. (2010) Pattern of homicides at mortuary of civic hospital Ahmedabad. Journal of Forensic Medicine and Toxicology, 27, 51-55.

[6] Shivkumar, B.C., Vishwanath, D. and Srivastava, P.C. (2011) Trends of Homicidal deaths at a tertiary care centre, Bengaluru. Journal of the Indian Academy of Forensic Medicine, 33, 120-125 
[7] Gupta, A., Mukta, R., Mittal, A.K. and Dikshit, P.C. (2004) A study of homicidal deaths in Delhi. Medicine, Science and the Law, 44, 127-132. doi:10.1258/rsmmsl.44.2.127

[8] Gupta, S. and Prajapati, P. (2009) Homicide trends at Surat region of Gujarat, India. Journal of Forensic Medicine \& Toxicology, 26, 45-48.

[9] Vij, A., Menon, A., Menezes, R.G., Kanchan, T. and Rastogi, P. (2010) A retrospective review of homicides in Mangalore, South India. Journal of Forensic and Legal Medicine, 17, 312-315. doi:10.1016/j.jflm.2010.04.012

[10] Gadge, S., Batra, A.K., Kuchewar, S.V., Meshram, R.D. and Dhawane, S.G. (2011) Medico-legal study of homicide in and around GMC Aurangabad. Medico-Legal Update, 1, 56-58.

[11] Buchade, D. and Mohite, S. (2010) Trends in culpable homicide amounting to murder in the city of Greater Mumbai: A five-year study. Medico-Legal Update, 10, 12-14.

[12] Mohanty, M.K., Mohanty, S. and Acharya, S. (2004) Circumstances of crime in homicidal deaths. Medicine, Science and the Law, 44, 160-164. doi:10.1258/rsmmsl.44.2.160

[13] Eze, U.O., Akang, E.E.U. and Odesanmi, W.O. (2011) Pattern of homicide coroner's autopsies at university college hospital, Ibadan, Nigeria: 1997-2006. Medicine, Science and the Law, 51, 43-48. doi: $10.1258 / \mathrm{msl} .2010 .010082$

[14] Collins, K.A. and Presnell, S.E. (2006) Elder homicide: A 20-year study. American Journal of Forensic Medicine and Pathology, 27, 183-187. doi:10.1097/01.paf.0000203268.30433.01

[15] Niemcunowicz-Janica, A., Janica, J., Rydzewska-Dudek, M., Załuski, J., Dopierała, T., Wardaszka, Z., PtaszyńskaSarosiek, I. and Okłota, M. (2006) Medico-legal and victimology aspects of homicides in the material of Bialystok Institute of Forensic Medicine in the years 19822003. Archiwum Medycyny Sadowej i Kryminologii, 56, 5-8.

[16] Hilal, A., Cekin, N., Gülmen, M.K., Ozdemir, M.H. and Karanfil, R. (2005) Homicide in Adana, Turkey: A 5-year review. American Journal of Forensic Medicine and Pathology, 26, 141-145.

[17] Bashir, M.Z., Saeed, A., et al. (2004) A study of pattern of homicidal deaths in Faisalabad: 2001-2002. Journal of Ayub Medical College, Abbottabad, 16, 57-59.
[18] Marri, M.Z., Bashir, M.Z., Munawar, A.Z., Khalil, Z.H. and Khalil, I.R. (2006) Analysis of homicidal deaths in Peshawar, Pakistan. Journal of Ayub Medical College, Abbottabad, 18, 30-33.

[19] Bhupinder, S., Kumara, T.K. and Syed, A.M. (2010) Pattern of homicidal deaths autopsied at Penang Hospital, Malaysia, 2007-2009: A preliminary study. Malaysian Journal of Pathology, 32, 81-86.

[20] Kumar, V., Mae Li, A.K., Zanial, A.Z., Lee, D.A. and Salleh, S.A. (2005) A study of Homicidal deaths in medicolegal autopsies at UMMC, Kuala Lumpur. Journal of Clinical Forensic Medicine, 12, 254-257. doi:10.1016/j.jcfm.2005.02.007

[21] Edirisinghe, P.A. and Kitulwatte, I.D. (2009) Extreme violence-homicide: An analysis of 265 cases from the offices of JMO Colombo and Ragama: A study from Sri Lanka. Legal Medicine, 11, 363-365. doi:10.1016/j.legalmed.2009.02.079

[22] Meel, B. (2007) Trends in firearm-related deaths in the Transkei region of South Africa. American Journal of Forensic Medicine and Pathology, 28, 86-90. doi:10.1097/01.paf.0000257371.80947.56

[23] Lee-Germon, M., MacNeill, S., Rizet, D. and McDermott, S.D. (2011) Homicide/suspicious death statistics for cases submitted to the forensic science laboratory in the Republic of Ireland for 2004-2008. Medicine, Science and the Law, 51, 146-150. doi:10.1258/msl.2010.010139

[24] Padosch, S.A., Passinger, C., Schmidt, P.H. and Madea, B. (2010) Analysis of 1989-1999 homicide crimes in the catchment area of the Bonn Institute of Forensic Medicine with reference to selected aspects. American Journal of Forensic Medicine and Pathology, 31, e3.

[25] Vougiouklakis, T. and Tsiligianni, C. (2006) Forensic and criminologic aspects of murder in North-West (Epirus) Greece. Journal of Clinical Forensic Medicine, 13, 316320. doi:10.1016/j.jcfm.2006.06.015

[26] Avis, S.P. (1996) Homicide in New Foundland: A 9-year review. Journal of forensic Science, 41, 101-105.

[27] Falzon, A.L. and Davis, G.G. (1998) A 15-year retrospective review of homicide in the elderly. Journal of Forensic Sciences, 43, 371-374.

[28] Henderson, J.P., Morgan, S.E., Patel, F. and Tiplady, M.E. (2005) Patterns of non-firearm homicide. Journal of Clinical Forensic Medicine, 12, 128-132. doi:10.1016/j.jcfm.2004.10.011 